\title{
Mouse project to find each gene's role
}

\section{International Mouse Phenotyping Consortium launches with a massive funding commitment.}

An ambitious effort to identify the function of every gene in the mouse genome looks set to provide scientists with the ultimate mouse model of human disease.

The International Mouse Phenotyping Consortium (IMPC) has yet to find all of the US\$900 million it needs to complete its task over the next decade. But at a meeting on mouse models of human diseases in London, where the project was unveiled last week, scientists announced a commit-

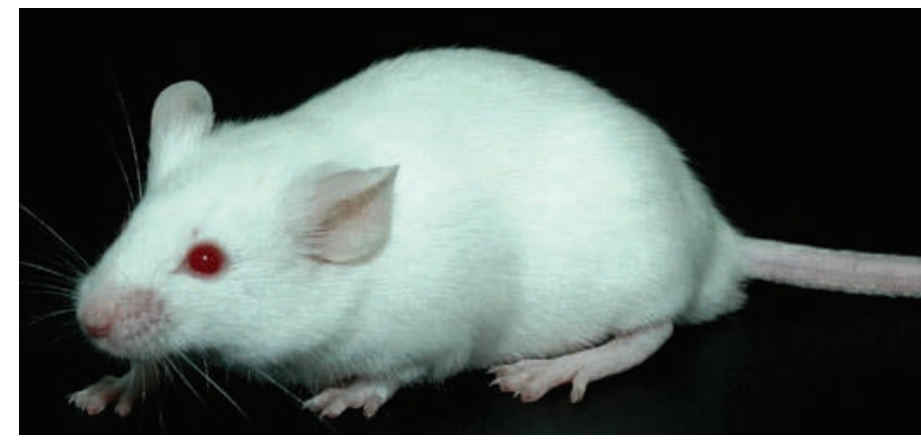

Making thousands of strains of knockout mice will build a powerful database.

phenotyping of the complete genome internationally, like we did the human and mouse genome," says geneticist Mark Moore, a consultant for the NIH, the MRC and the Wellcome Trust UK medical funding charity, who heads the IMPC. The consortium, which will involve clinical as well as basic research scientists, will do primary phenotypic screens on 4,000 knockout mice in its first five years. Any researcher may request a particular gene to be prioritized ment of $\$ 110$ million from the US National Institutes of Health (NIH) in Bethesda, Maryland over the next five years.

"The project will explain the genes - it is going to be transformative for biology," says James Battey, director of the National Institute on Deafness and Other Communication Disorders. This is one of the nine NIH institutes that have agreed to set aside $\$ 11$ million from their budgets to match the $\$ 11$ million put up by Francis Collins from his own budget as NIH director.

The IMPC aims to take mice of identical genetic background and to create viable strains in which one of the 20,000 or so genes in the mouse genome is knocked out, or deactivated. The knockout strains will then be put through rigorous, systematic phenotypic screens, which will check for physical and behavioural differences. The information will be stored in a purpose-built, open-access database.

Scientists would, for example, be able to turn to the database to learn more about an unfamiliar gene signalled in a genome-wide association study in humans as being possibly relevant to a particular disease. Making the mutant animal and phenotyping it in a lab could take three years.

According to Battey, the NIH thinks that its investment in the large-scale programme will actually save money in the long run, because it already spends "hun-

Commission, which sponsored the meeting and has spent close to $€ 250$ million (US\$305 million) over the past ten years to pioneer systematic phenotyping of mice, and to generate mutant mice. But Leszek Borysiewicz, chief executive of the UK Medical Research Council (MRC) in London, warned at the meeting that the commission's politicians would need a lot of convincing that mouse genomics was more deserving of funds than other scientific projects.

Scientists at the meeting, however, argue that the IMPC's goals will eventually be achieved, even if the timetable has to be stretched, simply because the work is so vital. The mouse genome was the first to be sequenced after the human because of its importance as a laboratory model. "But it soon became clear that it is impossible to predict function directly from sequence," says Paul Schofield, a geneticist at the University of Cambridge, UK, who helped to organize the meeting. "Also, there are black holes in the genomes where we simply don't know what the genes do - the mouse phenotype database would give us traction."

Mouse 'clinics' have sprung up around the world to screen mutant mice for crude phenotypes - such as heart defects - and to perform secondary screens to investigate the changes in more detail. But it is already clear that even this is not enough. Gene expression, and the resultant phenotype, are profoundly influenced by envidreds of millions of dollars per year" supporting small-scale grants for individual scientists wanting to create and phenotype their own particular gene of interest.

But the launch of the visionary programme comes at a time of global financial crisis and may have trouble finding additional funders. Some scientists had looked to the European
"No question, the mouse is where the action is." ronment, and many of these mice are raised in a stressed environment for the purposes of experiments - for example, being fed high fat diets or subjected to infection. Much more will be learnt by comparing phenotype screens carried out on mutant mice raised in a normal environment, say project scientists.

"It makes sense to coordinate the systematic for knocking out in this first phase, although a proportion will also be selected at random.

The IMPC is already discussing with the scientific community exactly what types of phenotyping should be carried out, and what environmental challenges the mice should face in later stages of the project. It is also considering including a colony of ageing mice: "This would increase costs because the mice would have to be housed for so long, but age-related diseases are at the top of everyone's agendas," says Moore.

\section{Source of drugs}

"The IMPC sounds expensive but it is not compared with other genomic resources," adds Moore. "The database only needs to help industry to develop a handful of multibilliondollar blockbuster drugs and it will have paid for itself."

"The initiative will save us time and money, which will help us provide drugs in return," agrees David Frendewey, an associate director of Regeneron Pharmaceuticals, headquartered in Tarrytown, New York. "No question, the mouse is where the action is." Yet turning drug companies' interest into hard currency won't be easy. "Industry will participate in kind, but maybe not with cash — we are no longer a bottomless pit of money," says Malcolm Skingle, director of academic liaison at GlaxoSmithKline in Stevenage, UK.

And genome engineer Francis Stewart of the Technical University of Dresden, Germany, says that focusing on the commercial benefits of the project misses the point. "Through the IMPC, we have a historic opportunity to systematically learn everything about a mammal, for the first time," he says. "Let's not lose the vision by sidetracking into applications issues just to please politicians."

Alison Abbott 